\title{
PENERAPAN USABILITY TESTING UNTUK PENGUKURAN KUALITAS SISTEM ENTERPRISE RESOURCE PLANNING (ERP) (STUDI KASUS: PT. TITIS SEMPURNAH PRABUMULIH)
}

\author{
Ulpa Permata Sari $^{1}$, Megawaty ${ }^{2}$ \\ ${ }^{1}$ Fakultas Ilmu Komputer, Universitas Bina Darma \\ Email: ulpapermatasari@gmail.com¹, megawaty@binadarma.ac.id ${ }^{2}$
}

\begin{abstract}
Titis Sempurna is a company engaged in oil and gas, which has implemented an ERP (Enterprise Resources Planning) system. website-based which means the system can be used where I am and anytime, but website-based ERP systems have weaknesses, the possibility of the system being hacked by hackers because everyone can find out the address of the ERP system in PT.Titis Sempurna.This certainly can lead to concerns of users of ERP systems that include parts of accounting, purchase, warehouse, and human resource development (HRD), because the system cannot be guaranteed security. other than that the ERP system is also too complex and difficult for users to understand as in the purchase user often experiences constraints when the user wants to import PO data. This happens because the use, implementation and integration of the ERP system is difficult to apply in a company and therefore the need for usability testing to measure the quality of the ERP system is done so that the level of usability or usability of the system is expected and later the results of this research are expected later can provide usability or system usability which includes Learnability, Efficiency, Memorability, Errors, and Satisfaction ERP systems for the future.
\end{abstract}

Keywords: PT.Titis Sempurna, ERP, Usability

\begin{abstract}
Abstrak
PT.Titis Sempurna adalah perusahaan yang bergerak dibidang minyak dan gas, yang telah menerapkan sistem ERP (Enterprise Resources Planning). berbasis website yang artinya sistem dapat digunakan dimana saya dan kapan saja akan tetapi sistem ERP berbasis website memiliki kelemahan salasatunya memungkinan sistem dapat di retas oleh hacker karna setiap orang dapat mengetahui alamat dari sistem ERP yang ada di PT.Titis Sempurna.hal ini tentu dapat menimbulkan kekhawatiran dari pengguna sistem ERP yang meliputi bagian dari accounting, purchase, warehouse, dan human resource development (HRD), karna sistem tidak bisa dijamin keamanannya. selain itu sistem ERP juga terlalu kompleks dan sulit untuk dipahami user seperti pada bagian purchase user sering mengalami kendala salasatunya ialah pada saat user ingin mengimputkan data PO. Hal ini terjadi karna penggunaan, pengimplementasian dan pengintegrasian dari sistem ERP sulit untuk di terapkan disebuah prusahaan maka dari itu perlu dilakukannya penerpan usability testing untuk mengukur kualitas sistem ERP hal ini dilakukan agar diketahui tingkat usability atau kebergunaan dari sistem tersebut dan diharapkan nantinya hasil dari penelitian ini dapat memberikan kebergunaan atau usability sistem yang meliputi Learnability, Efficiency, Memorability, Errors, dan Satisfaction sistem ERP untuk kedepannya.
\end{abstract}

Kata Kunci: PT.Titis Sempurna, ERP, Usability

\section{Pendahuluan}

Pada saat ini peranan Sistem Informasi tidak dapat dipungkiri lagi telah menjadi salah satu elemen penting dalam mendukung proses bisnis di perusahaan. Setiap perusahaan dituntut untuk selalu memperhatikan teknologi yang dimiliki secara keseluruhan agar dapat terus mengikuti perubahan dari 
perkembangan teknologi. Dengan memanfaatkan teknologi informasi, perusahaan dapat menjalankan proses bisnis dengan lebih cepat dan dapat mengolah data dengan lebih akurat. Hal ini terjawab dengan hadirnya sebuah sistem informasi ERP (Enterprise Resources Planning). ERP adalah sebuah sistem informasi yang dapat mengintegrasikan fungsi pemasaran, fungsi pemesanan, fungsi keuangan, fungsi persediaan, fungsi sumberdaya dan lain sebagainya. Sekarang ini ERP telah berkembang sebagai sistem yang dapat mengintegrasikan semua kegiatan perusahaan kepusat penyimpanan data sehingga dapat dengan mudah diakses oleh semua bagian yang membutuhkan termasuk mengintegrasikan sistem dengan pemasok[1]

Sala satu prusahaan yang menerapkan sistem ERP ini yaitu PT.Titis Sempurna, PT.Titis Sempurna sudah cukup lama menerapkan sistem ERP sekitar 5 tahun dari tahun 2014 sampai dengan sekarang. PT.Titis sempurna adalah prusahaan yang bergerak dibidang minyak dan gas dengan mengelola gas mentah LPG menjadi gas siap. aktivitas yang sering dilakukan di sistem ERP ini yaitu aktivitas pada bagian PO (purchase) maka dari itu penelitian kali ini lebih terfokus pada bagian PO (purchase) karna hampir setiap hari bagian dari PO ini melakukan transaksi di sistem ERP transaksi yang dillakukan disistem ERP ini meliputi, pemesanan barang yang dilakukan karyawan dari lapangan dan pembuatan purchase requisition yang dibuat oleh pihak internal prusahaan. untuk melakukan pemesanan PO karyawan dari bagain lapang terlebih dahulu meminta from PO kebagai dari purchase kemudian mengisi from PO tersebut, untuk dilaporkan kebagian HRD, setelah bagian HRD memeriksa from PO dari bagian lapangan lalu bagian HRD kemudian menandatangani from PO tersebut untuk diberikan ke bagian purchase agar dilakukan proses pemesana, akan tetapi pada saat akan melakukan proses pemesanan PO bagian purchase sering menghadapi masalah seperti ketika ingin mengimputkan data PO kedalam sistem, admin dari purchase tidak bisa mengcopy paste data yang sudah diinputkan sebelumnya apabila ada kesamaan data pada from PO.

selain itu sistem ERP pada bagian purchase juga tidak bisa melakukan pengeditan data apabila terjadi kesalahan dalam pembuatan data PO, maka bagian purchase harus mengcancel data PO yang sudah dibuatkan sebelumnya hal ini tentu akan berdampak pada pembuatan PO ulang dengan mengharuskan pemesan PO melalui proses awal permintaan ulang kembali, yang mengharuskan peminta PO untuk melakukan proses ulang seperti yang sudah disebutkan sebelumnya berdasarkan data diatas dan permasalahan yang ditemukan maka penulis ingin mengukur tingkat dimana pengguna mampu berinteraksi secara efektif dengan sistem ERP menggunakan metode usability. Sebelum melakukan pengukuran kinerja sistem ERP, perlu di ingat bahwa usability adalah suatu tolak ukur yang digunakan untuk mengetahui kinerja dari suatu sistem dengan mengujinya langsung kepada pengguna[2] Selain itu sistem ERP juga terlalu banyak fitur dan terlalu kompleks untuk digunakan oleh user, Maka dari itu perlu dilakukannya analisis atau pengukuran kinerja dari sistem ERP untuk mengetahui apakah sistem tersebut telah memenuhi kebutuhan dan tujuan dari prusahaan. Dengan ditemukannya permasalahan-permasalahan di atas maka perlu dilakukan penelitian tentang Penerapan Usability Testing Untuk Pengukuran Kualitas Sistem Enterprise Resource Planning (ERP)

\section{Metodologi Penelitian}

\subsection{Landasan Teori}

Dari penelitian-penelitian yang sudah penulis pelajari kemudian penulis menemukan difinisi-difinisi dari setiap kata yang terdapat didalam judul penulis seperti Sistem adalah satu jaringan kegiatan dari aturanaturan yang saling berhubungan dan berkumpul bersama-sama agar dapat melakukan kegiatan ataupun untuk menyelesaikan tujuan tertentu. Pendekatan sistem yang merupakan jaringan kerja dari aturan penyelesaian kegiatan lebih ditekankan pada urutan-urutan operasi didalam sistem itu sendiri[3] selain juga ada ERP dapat didifinisikan sebagai sistem informasi yang mampu membantu prusahaan untuk meningkatkan efektifitas dan efesiensi dari prusahaan tersebut dengan mengintegrasikan informasi yang ada diprusahaan tersebut dari macam-macam aspek sumberdaya yang ada seperti (SDM, Keuangan, Persediaan, Pemesanan)[4] Dan untuk difinisi dari usability sendiri adalah menurut ISO 9241:11 (1998) dalam[5] disebutkan bahwa usability adalah sejauh mana suatu produk dapat digunakan oleh pengguna tertentu untuk mencapai target yang ditetapkan dengan efektivitas, efesiensi dan mencapai kepuasan 
penggunaan dalam konteks tertentu. Yang mana untuk komponen dari usability itu sendiripun terdiri dari 5 variabel yaitu meliputi, learnability artinya seberapa mudah pengguna dalam menggunakan website tersebut, Efficiency seberapa cepat pengguna dapat menyelesaikan tugas yang pada website, memorability seberapa mudah desain interface website tersebut diingat, Error ada berapa banyak kesalahan yang sering dilakukan pengguna, statifaction yaitu kepuasan pengguna dalam menggunakan website tersebut [6].

\subsection{Penelitian Terdahulu}

Pada penelitian ini penulis mengambil penelitian terdahulu untuk dijadikan bahan referensi dalam penulisan ini "Pengukuran Tingkat Ketergunaan (Usability) Sistem Informasi Keuangan Studi Kasus: Duta Wacana Internal Transaction (Duwit)"'[7] penelitian bertujuan untuk mengukur tingkat usability dari sistem informasi keuangan, agar diketahui seberapa besar tingkat pemahaman dan kesulitan user dalam menggunakan sistem transaksi melalui antar muka Duwit yang sudah dibuat, Hasil dari penelitian ini adalah tingkat ketergunan (usability) dari sistem Duwit, apakah mudah dipelajari, efisien, pada saat penggunannya selain itu penulis juga memiliki referensi lain dalam melakukan penelitian ini yaitu "Evaluasi Website E-Ticketing dengan Menggunakan Metode Usability Testing dan Wammi"[8]hasil dari penelitian ini diharpkan nantinya dapat memberikan manfaat yaitu mengetahui apakah dua website eticketing yang diantaranya adalah website traveloka.com dan website tiket. com telah memenuhi standar usability dan dapat memberikan rekomendasi terhadap website-website tersebut sesuai dengan standar usability dan wammi.referensi lain yang penulis gunakan dalam pembuatan laporan penelitian ini yaitu "Pengujian Hipotesis Penelitian Survey Usability Website ResearchGate Menggunakan SmartPLS" [9] adapun tujuan dari penelitian ini yaitu untuk mengetahui tingkat usability dari website researchGate dengan menggunakan SmartPLS, smartPLS adalah sebuah tool yang digunakan untuk menangani banyak variabel responden sekaligus dan dari hasil penelitian ini menghasilkan nilai p-value senilai 0.029 dan 0.009. yang artinya hasil tersebut berpengaruh positif terhadap tingkat usability dan disarankan bagai mahasiswa untuk melakukan publikasi karya tulis di ResearchGate tersebut.

\subsection{Metode Penelitian}

Untuk melakukan penelitian ini penulis menggunakan metode kuantitatif dengan penelitian survei Menurut[10] pengertian metode kuantitatif adalah Metode kuantitatif dapat diartikan sebagai metode penelitia yang berlandaskan pada filsafat positivisme, Sedangkan penelitian survei yaitu penelitian yang digunakan untuk menjelaskan hubungan kausal dan pengujian hipotesis.

\subsubsection{Metode Usability Testing}

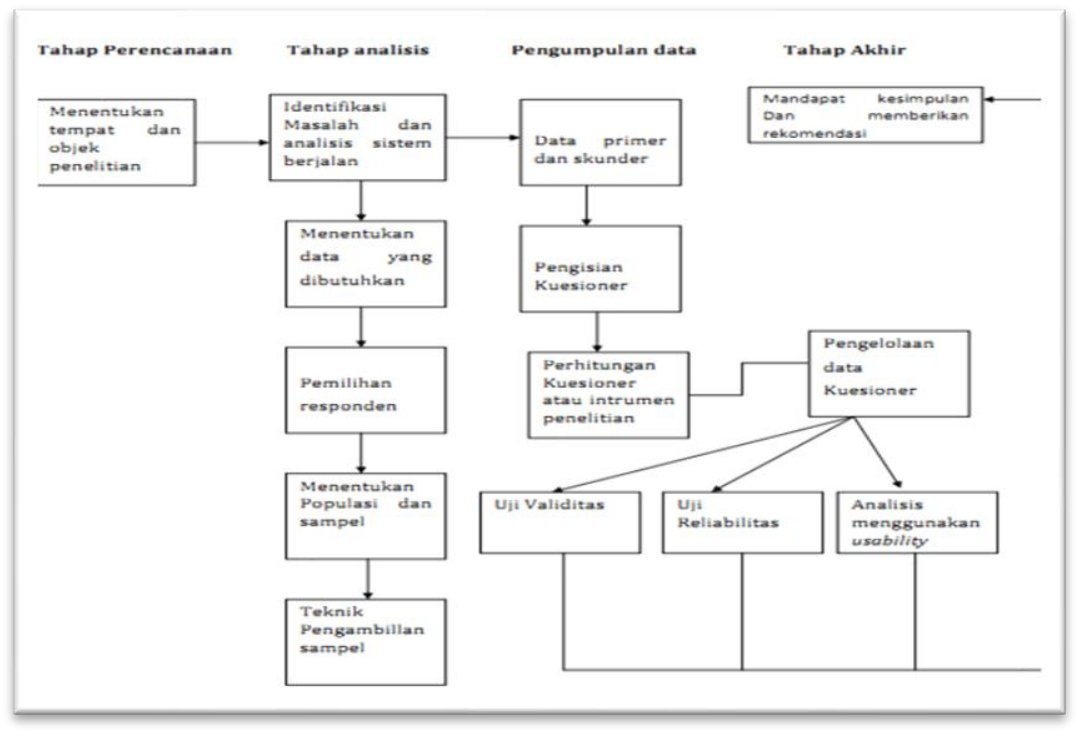

Gambar 3.1. Alur Metode Penelitian Usability 
Gambar diatas menjelaskan tahapan-tahapan yang ada dalam metode usability testing yaitu sebagai berikut:

1. Tahap perencanaan

Untuk melakukan tahapan awal ini kegiatan yang dilakukan oleh penulis yaitu menentukan tempat dan objek penelitian yang mana hal tersebut dapat kita lihat pada penjelasan dibawah ini yaitu sebagai berikut :

- Menentukan Tempat dan Objek Penelitian Untuk melakukan penyusunan laporan ini hal pertama yang dilakukan penulis ialah menentukan tempat penelitian terlebih dahulu yang mana dalam hal ini penulis memilih PT.Titis Sempurna Prabumulih sebagai tempat penelitian.

2. Tahap Analisis

- Identifikasi masalah dan analisis sistem berjalan hal ini dilakukan agar tidak terjadi keraguraguan dalam membuat rumusan masalah, batasan-batasan masalah, tujuan dan maanfaat dari penelitian

- Menentukan data yang dibutuhkan Pada pengumpulan data kali ini peneliti menggunakan metode pengumpulan data primer dan sekunder metode pengumpulan data primer

3. Tahap Pemilihan Responden Untuk memilih dan menentukan responden ini penulis memilih berdasarkan tiga tingkatan yaitu pengguna awam, aktif, trampil

- Menentukan Populasi menurut[10] populasi diartikan sebagai wilayah generalisasi yang terdiri atas objek/subjek yang mempunyai kualitas dan karakteristik tertentu yang ditetapkan oleh peneliti dan ditarik kesimpulannya. Adapun Jumlah responden yang dilibatkan dalam penelitian ini adalah 12 responden

- Menentukan Sampel pada penelitian kali ini penulis mempunyai 12 sampel yang mana hal tersebut terdiri dari 8 (Delapan) pengguna aktif, 1 (Satu) pengguna trampil dan 3 (Tiga) pengguna awam.

- Teknik Pengambilan sampel Adapun teknik pengambilan sampel yang penulis gunakan yaitu menggunakan teknik purposive sampling berarti teknik pengambilan sampel secara sengaja penilaian sampel berdasarkan "penilaian" (judgment) peneliti mengenai siapa-siapa yang cocok untuk dijadikan sampel [11] yang mana dalam hal ini penulis menggunakan pengguna sistem atau orang yang sering menggunakan sistem ERP PT.Titis sebagai pengguna aktif yaitu bagaian dari staff accounting, purchase, hrd dan warehouse, kemudian pengguna trampil yaitu orang yang sangat tau mengenai sistem ERP tersebut yang dalam hal ini penulis memilih bagian Staff TI, dan pengguna awam yang dalam hal ini jarang menggunakan sistem yaitu bagaian dari staff maintenance yang mana untuk setiap tingkatan responden berdasarkan status penggunanya, jenis kelamin dan umur dapat kita lihat pada tabel dinawah ini yaitu sebagai berikut:

Tabel 1. responden berdasarkan status pengguna

\begin{tabular}{|c|l|l|l|}
\hline $\begin{array}{c}\text { Responden } \\
\text { ke }\end{array}$ & \multicolumn{1}{|c|}{$\begin{array}{c}\text { Status } \\
\text { Pengguna }\end{array}$} & \multicolumn{1}{|c|}{ Nama } & \multicolumn{1}{|c|}{ Intansi/jabatan } \\
\hline 1 & Aktif & M.Tafsir & Warehouse Officer \\
\hline 2 & Aktif & Suparmo & Menejer Keuangan \\
\hline 3 & Aktif & Roslina & Adm O2m \\
\hline 4 & Aktif & Made Arya & Staff HRD \\
\hline 5 & Aktif & Hendri Hariyono & Staff Procrutment \\
\hline 6 & Aktif & Randy Widiakso & Staff Procritment \\
\hline 7 & Aktif & Isri Embar & Staff Ganeral Manajer \\
\hline 8 & Aktif & Helfi Mega Sari & Lap Spesialist \\
\hline 9 & Trampil & Iny. Suarsana & Ict Supu \\
\hline 10 & Awam & Sefti Monic Taroma & Engineer \\
\hline 11 & Awam & Belly Kurniawan & Operator Lpg Plane \\
\hline 12 & Awam & Redi Saputra & Logistik \\
\hline
\end{tabular}

( sumber PT.Titis sempurnah prabumulih) 
Dari tabel diatas dapat kita lihat bahwa terdapat 8 orang responden untuk pengguna aktif atau $60 \%$, untuk pengguna trampil terdapat satu orang atau $10 \%$ dan pengguna awam 3 orang atau $30 \%$ selain jumlah responden penulis juga mengklasifikasikan responden berdasarkan umur dan jenis kelamin yang mana hal tersebut dapat dilihat pada tabel dibawah ini:

Tabel 2. Jenis Kelamin responde

\begin{tabular}{|c|c|}
\hline Jenis Kelamin & Jumlah \\
\hline Laki-Laki & 9 Orang \\
\hline Perempuan & 3 Orang \\
\hline
\end{tabular}

(sumber PT.Titis sempurnah prabumulih)

Dari tabel diatas dapat diketahui bahwa dari jumlah total 12 responden terdapat 9 orang atau $90 \%$ berjenis kelamin laki-laki dan 3 orang atau $10 \%$ dari total kuesioner berjenis kelamin perempuan.

Tabel 3. Responden Berdasarkan Umur

\begin{tabular}{|c|c|}
\hline Umur & Jumlah \\
\hline$<30$ & 4 \\
\hline $30-40$ & 4 \\
\hline$>40$ & 4 \\
\hline
\end{tabular}

(sumber PT.Titis sempurnah prabumulih

Dari tabel diatas dapat diketahui bahwa dari jumlah total 12 responden, terdapat 4 orang responden yang berumur kurang dari 30 atau 33,3\%, 4 orang responden yang berumur $30-40$ tahun atau 33,3\%, dan 4 orang yang berumur di atas 30 atau $33,3 \%$

4. Tahap Pengumpulan data Tahap ini adalah tahapan yang berisi tentang proses dalam pengumpulan data baik itu data Skunder ataupun data Primer

- Studi Pustaka Studi Kepustakaan (Library Study) ini adalah termasuk pengumpulan data skunder yang artinya yaitu pencarian data melalui media buku-buku maupun media internet yang berhubungan dengan sistem ERP ataupun judul dari penelitian yang dilakukan oleh penulis

- Wawancara Wawancara (interview) adalah pengumpulan data primer yang mana artinya yaitu penulis menanyakan secara langsung kepada pihak-pihak yang bersangkutan mengenai sistem ERP

- Pengisian Kuesioner Untuk melakukan pengukuran sistem ERP yang ada di PT.Titis Sempurna Prabumulih maka penulis memerlukan kuesioner yang digunakan untuk mengetahui persepsi atau pendapat dari pengguna sistem ERP yang ada di PT.TitisSempurna Prabumulih tersebut,

- Instrumen Penelitian menurut [12] adalah salasatu kegiatan dalam penelitian untuk melakukan pengukuran terhadap fenomena sosial maupun alam Karna instrumen penelitian akan digunakan untuk melakukan pengukura dengan tujuan menghasilkan data kuantitatif yang akurat maka setiap instrumen harus memiliki skala. Dan skala yang digunakan untuk mengukur kualitas sistem ERP adalah skala likert. Adapun tabel bobot nilai yang digunakan penulis kepada responden yaitu dengan menggunakan skala 1-5 yaitu sebagai berikut :

Tabel 4. Bobot Nilai

\begin{tabular}{|c|c|c|c|c|c|}
\hline PK & STS & TS & N & S & SS \\
\hline Nilai & 1 & 2 & 3 & 4 & 5 \\
\hline
\end{tabular}

Keterangan :

$\begin{array}{ll}\text { PK } & =\text { Pernyataankuesioner } \\ \text { STS } & =\text { Sangat Tidak Setuju } \\ \text { TS } & =\text { Tidak Setuju }\end{array}$




$\begin{array}{ll}\mathrm{N} & =\text { netral } \\ \mathrm{S} & =\text { Setuju } \\ \mathrm{SS} & =\text { Sangat Setuju }\end{array}$

5. Tahap Evaluasi dan Hasil

- Mengelola data Kuesioner Pada tahapan pengelolaan data kuesioner ini penulis menggunakan microsoft excel sebagai alat untuk menghitung data-data kuesioner dari karyawan yang ada di PT.Titis Sempurna Prabumulih

- Uji Validitas suatu Kuesioner dikatakan valid apabila nilai $r$-hitung lebih besar dari nilai $r$ tabel. Kali ini penulis menggunakan $r$-tabel dengan taraf signifikat yaitu sebesar $5 \%$ jadi untuk menentukan nilai $r$-tabel suatu kuesioner penulis melihat jumlah responden yang ada

- Uji reliabilitas untuk menghitung suatu instrumen rumus yang penulis gunakan yaitu rumus $\left(\mathrm{r}_{\mathrm{ac}}\right)$ yang dapat dilihat pada rumus dibawah ini yaitu sebagai berikut:

$$
r_{a c}=\left(\begin{array}{c}
k \\
k-1
\end{array}\right)\left[1-\frac{\sum \sigma b^{2}}{\sigma t^{2}}\right]
$$

- Menghitung nilai Kuesioner agar didapatkan nilai Y dan X maka peneliti menggunakan rumus sebagai seperti dibawah ini yaitu sebagai berikut :

$\mathrm{Y}=$ Bobot Nilai Tertinggi $\mathrm{x}$ Jumlah Responden

$\mathrm{X}=$ Bobot Nilai Terendah $\mathrm{x}$ Jumlah Responden

- Menghitung Nilai Akhir Untuk menghitung hasil akhir cara yang harus dilakukan adalah menjumlah seluruh nilai dari variabel lalu dibagi dengan kelima variabel usability untuk lebih jelasnya adapun rumus yang digunakan yaitu sebagai berikut:

$$
\frac{H K}{J K}=\mathrm{N}
$$

Keterangan :

HK = Hasil Nilai Komponen

$\mathrm{JK}=$ Jumlah Komponen

$\mathrm{N}=$ Hasil Akhir

Setelah didapatkan hasil akhir dari usability testing kemudiann penulis membuatkan laporan untuk nantinya dapat diambil kesimpulan dan diberikan rekomendasi agar sistem dapat lebih baik lagi kedepannya, untuk dapat mengetahui seberapa \% pengguna yang setuju bahwa sistem ERP ini baik untuk digunakan maka dapat dilihat pada tabel dibawah ini yaitu sebagai berikut :

Tabel 5. Parameter Bobot Nilai

\begin{tabular}{|c|c|}
\hline Bobot Nilai & Keterangan \\
\hline$<21 \%$ & Sangat Tidak Setuju \\
\hline $22,6 \%-31,2 \%$ & Tidak Setuju \\
\hline $32,2 \%-40,8 \%$ & Netral \\
\hline $41,8 \%-50,4 \%$ & Setuju \\
\hline$>51,1 \%$ & Sangat Setuju \\
\hline
\end{tabular}




\section{Hasil dan Pembahasan}

Dari hasil penelitian dengan menggunakan metode usability testing untuk mengukur kualitas sistem ERP PT.Titis sempurna penulis hanya membahas mengenai seberapa baik kualitas sistem ERP serta manfaat apa yang didapat dari diterapkannya sistem ERP yang ada di PT.Titis sempurna prabumulih yang di dapatkan oleh prusahaan ataupun pengguna sistem tersebut. Berikut penulis tampilkan tampilan sistem ERP yang ada diPT.Titis Sempurna yaitu sebagai berikut

\subsection{Tampilan Aplikasi Sistem Erp}

1. Halaman Login adalah tampillan awal yang mana untuk masuk kedalam sistem ERP admin harus terlebih dahulu memasukan id atau username yang sudah diberikan oleh pihak prusahaan.

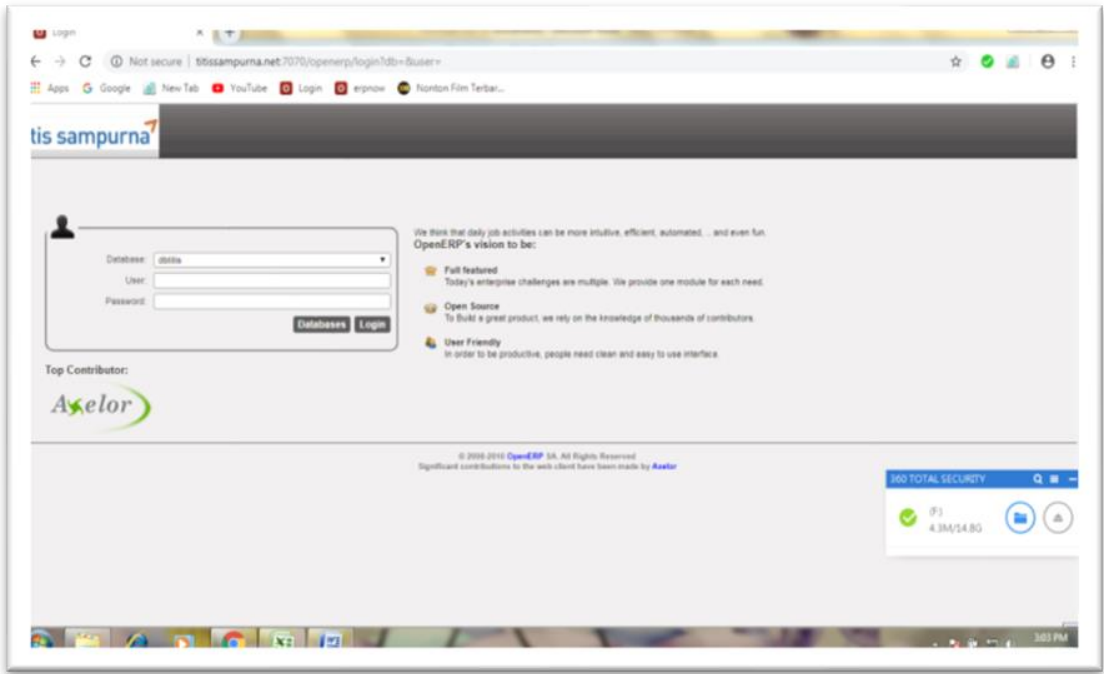

Gambar 1. halaman Login

2. Tampilan halaman PurchaseOrder Untuk tampilan menu awal dari purchase order menampilakan tampilan siapa saja yang telah mengakses sistem ERP pada bagian purchase dan kapan terakhir mereka mengaksesnya.

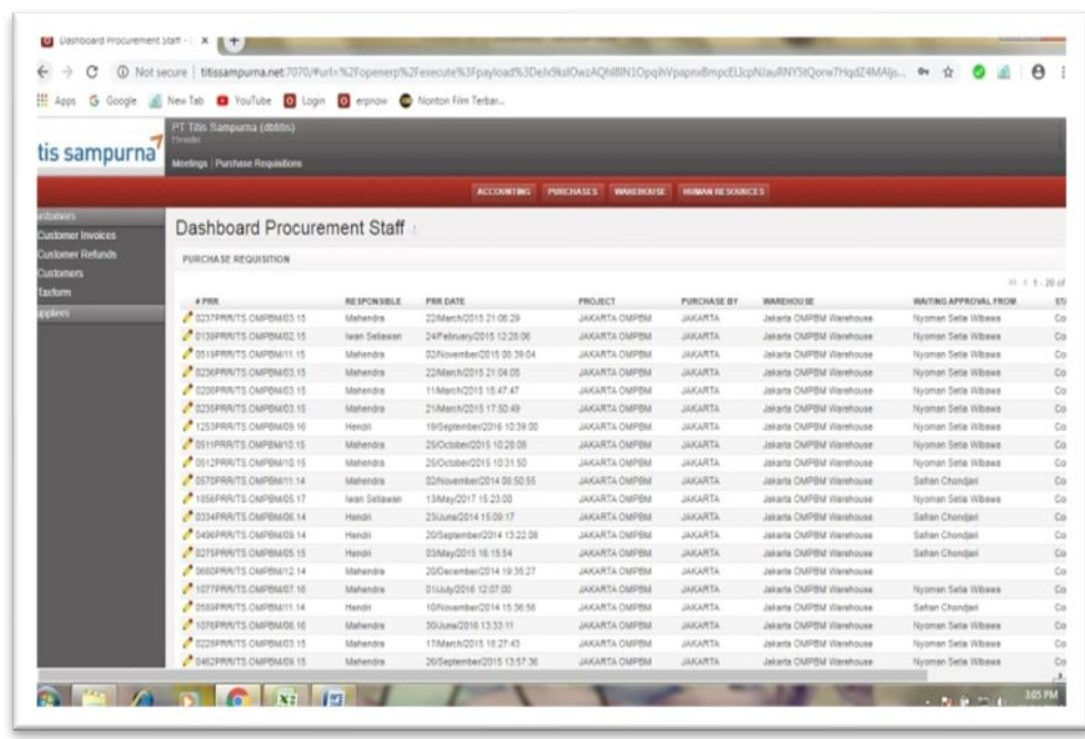

Gambar 2 Halaman PurchaseOrder 
3. Tampilan Menu Produk Pada tampilan menu produk diatas biasanya menampilkan secara keseluruhan barang-barang apa saja yang sudah diproses oleh prusahaan atau yang disetujui pemesanannya setelah pihak procrutment

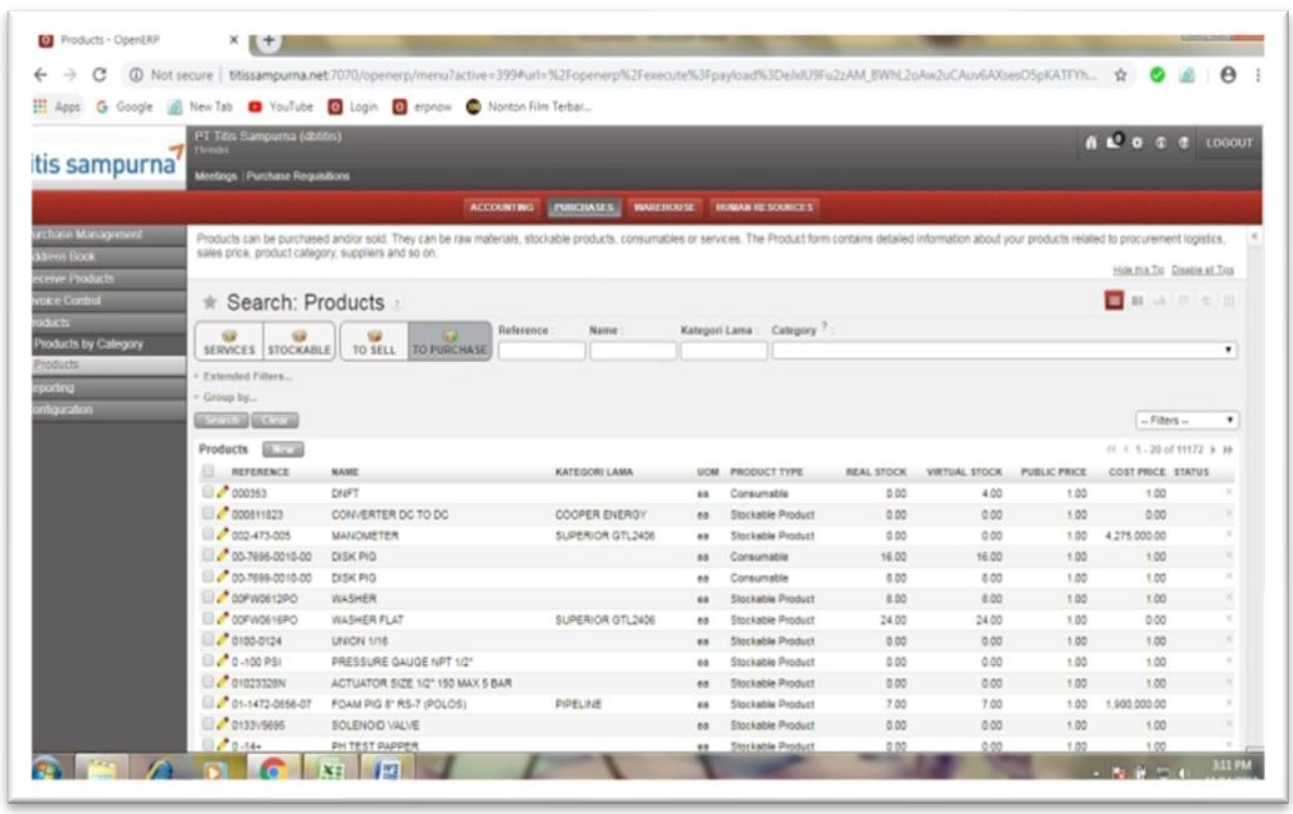

Gambar 3. Tampilan Menu Produk

\subsection{Hasil Rekapitulasi Jawaban RespondeN}

Untuk setiap masing-masing responden yang berjumlah 12 orang, dengan mengambil sampel dari 2 orang bagian accounting, 3 orang bagian purchase, 2 orang bagian warehouse, 1 orang bagian human resources yang mewakili pengguna aktif, kemudian ada 1 orang pada bagian TI yang mewakili pengguna trampil, dan 3 orang bagian maintenance yang mewakili pengguna awam. adapun data hasil rekapitulasi jawaban responden yang diolah menggunakan microsoft excel 2007 dapat dilihat pada tabel dibawah ini yaitu sebagai berikut:

Tabel 6. Hasil Rekapitulasi Responden

\begin{tabular}{|l|l|l|l|l|l|}
\hline No & Lernability & Efficiency & Memorability & Error & Satisfaction \\
\hline 1 & 20 & 20 & 20 & 22 & 22 \\
\hline 2 & 18 & 17 & 20 & 18 & 20 \\
\hline 3 & 20 & 20 & 15 & 17 & 17 \\
\hline 4 & 20 & 22 & 22 & 23 & 22 \\
\hline 5 & 25 & 25 & 23 & 25 & 20 \\
\hline 6 & 25 & 25 & 23 & 25 & 25 \\
\hline 7 & 20 & 20 & 18 & 18 & 18 \\
\hline 8 & 20 & 20 & 20 & 20 & 20 \\
\hline 9 & 20 & 20 & 18 & 18 & 18 \\
\hline 10 & 20 & 20 & 15 & 18 & 20 \\
\hline 11 & 20 & 17 & 18 & 18 & 20 \\
\hline 12 & 20 & 18 & 18 & 18 & 20 \\
\hline
\end{tabular}




\subsection{Hasil Rata-Rata Setiap Variabel}

Setelah terkumpulnya rekapitulasi jawaban dari responden kemudian langkah selanjutnya adalah mendapatkan hasil setiap variabel usability testing, agar hasil setiap variabel usability didapat maka langkah yang dilakukan adalah membagi jumlah jawaban masing-masing variabel dengan 5 (lima) variabel yang terdiri dari usability testing. Berikut ini tabel rata-rata setiap variabel

Tabel 7. Rata-Rata Setiap Variabel

\begin{tabular}{|l|l|}
\hline Variabel & Rata - Rata Presentase \\
\hline Learnability & $49,60 \%$ \\
\hline Efficiency & $48,80 \%$ \\
\hline Memorability & $46,00 \%$ \\
\hline Error & $48,30 \%$ \\
\hline Satisfaction & $48,40 \%$ \\
\hline
\end{tabular}

\subsection{Hasil Akhir}

Gabungan dari keseluruhan variabel usability testing penulis mendapatkan hasil akhir $(\mathrm{N})$ yaitu sebesar 48,16\% artinya kebanyakan karyawan yang telah menggunakan sistem ERP setuju bahwa sistem ERP baik untuk digunakan oleh karyawan PT.Titis dan untuk melihat hasil pembahasan diatas maka penulis telah presentasekan menjadi diagram yang mana dapat dilihat pada gambar dibawah ini

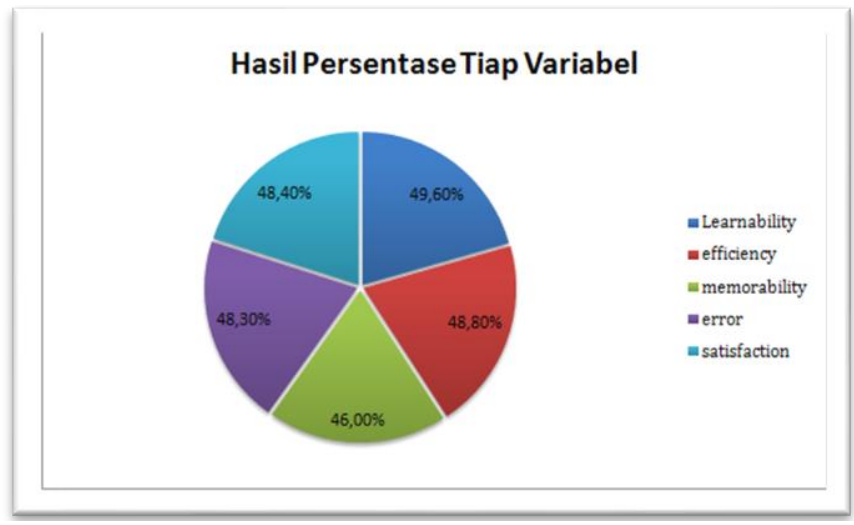

Gambar 4. Presentase Hasil Akhir

Dapat kita lihat bahwa diagram atau grafik diatas adalah nilai akhir dari hasil masing-masing variabel usability testing yang mana telah kita bahas pada Sub bab atau halaman sebelumnya. Kemudian langkah berikutnya adalah mengelompokkan hasil akhir dari setiap variabel usabillity testing dalam hal ini yaitu variabel, Lernability, Efficiency, Memorability, Error, Satisfaction. Untuk mencari nilai akhir agar nantinya didapatkan hasil akhir dari perhitungan usability testing sistem Enterprise Resource Planning (ERP) PT.Titis Sempurna Prabumulih tersebut.

\subsection{Pembahasan Hasil Akhir}

Untuk mencari nilai akhir dari usability testing ini sebelumnya penulis telah menjalas kan cara atau rumusnya pada bab sebelumnya yang mana hal tersebut dapat kita lihat pada bab 3 (Tiga). Agar didapatkan nilai akhir usability testing langkah yang harus dilakukan yaitu menjumblahkan seluruh variabel dari usability testing yang telah didapatkan dan dibahas pada halaman sebelumnya, kemudian setelah menjumlahkan seluruh nilai dari variabel usability testing selanjutnya penulis membaginya dengan jumlah variabel yang telah ditetapkan oleh usability testing itu sendiri dan berikut ini penulis sampaikan perhitungannya yaitu sebagai berikut : 


$$
\begin{aligned}
& \frac{49,60+48,80+46,00+48,30+48,40}{5}=N \text { maka }=\frac{240,80}{5}=48,16 \\
& \text { Maka } N=48,16=48 \%
\end{aligned}
$$

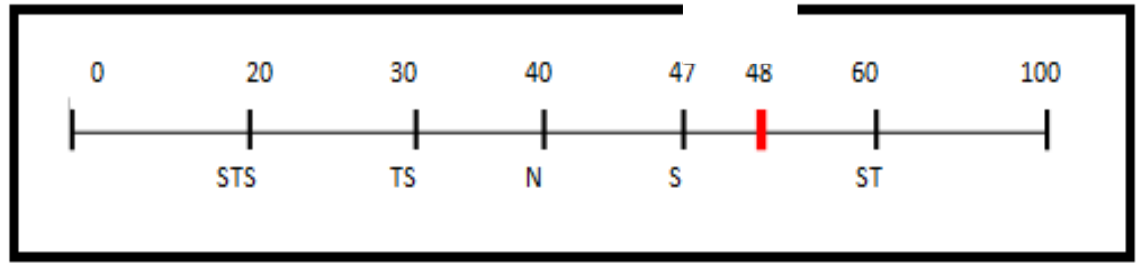

Gambar 5 Reting Scale

Dapat kita lihat pada gambar 4.5 diatas adalah gambar reting scale dari pembahasan hasil akhir usability testing yang mana dengan menjumlah seluruh variabel dan membaginya dengan jumblah variabel dari usability testing itu sendiri maka didapatlah hasil akhir dari perhitungan usability testing sistem ERP PT.Titis Sempurna Prabumulih dengan nilai sebesar 48,16\% atau dibulatkan menjadi $48 \%$ yang artinya kebanyakan dari responden atau pengguna sistem sistem ERP PT.Titis sempurna prabumulih menyatakan setuju jika sistem ERP ini baik untuk digunakan oleh penggunanya.

\section{Kesimpulan}

Dari penjelasan diatas dan pembahasan diatas maka didapatlah hasil $48,16 \%$ atau dibulatkan menjadi 48\% yang mana artinya adalah pengguna dari sistem ERP menyatakan setuju apabila sistem ERP baik untuk digunakan dan diterapkan pada prusahaan PT.Titis Sempurna tersebut yang mana hal ini dapat kita lihat dari perolehan setiap variabel usability testing itu sendiri dan berikut ini penulis sampaikan perhitungan masing-masing untuk setiap variabel dari usability testing yaitu sebagai berikut :

1. Lernability, mendapatkan skor nilai sebesar 152 dengan rata-rata yaitu $49,60 \%$ yang artinya sebagian pengguna atau responden setuju jika sistem ERP PT.Titis dikatakan baik atau mudah dalam penggunaannya.

2. Efficiency, mendapatkan skor nilai sebesar 146 dengan rata-rata yaitu 48,80\% yang artinya sebagian besar pengguna atau responden menyatakan setuju jika sistem ERP PT.Titis dikatakan baik atau Effisien dalam mencari informasi yang dibutuhkan

3. Memorability, mendapatkan skor nilai sebesar 139 dengan rata-rata yaitu $46,00 \%$ yang artinya kebanyakan dari pengguna atau responden setuju jika sistem ERP yang ada di PT.Titis dikatakan baik dan mudah untuk mengingat fungsi-fungsi dari setiap menu yang ada pada sistem ERP tersebut.

4. Error, mendapatkan skor nilai sebesar 145 dengan rata-rata yaitu 48,30\% yang artinya sebagian besar dari responden setuju jika sistem ERP PT.Titis dikatakan baik yang mana pengguna tidak menemukan link yang Error pada sistem ERP.

5. Satisfaction, mendapatkan nilai skor sebesar 145 dengan rata-rata 48,40\% artinya kebanyakan dari pengguna atau responden setuju jika sistem ERP PT.Titis dikatakan baik dan memuaskan digunakan.

\section{References}

[1] A. Wicaksono, H. H. Mulyo, and I. E. Riantono, "Analisis Dampak Penerapan Sistem ERP terhadap Kinerja Pengguna," Binus Bus. Rev., vol. 6, no. 1, p. 25, 2015, doi: 10.21512/bbr.v6i1.985.

[2] Yumarlin MZ, "Evaluasi Penggunaan Website Universitas Janabadra Dengan Menggunakan Metode Usability Testing," Inf. Interaktif, vol. 1, no. 1, pp. 34-43, 2016, [Online]. Available: journal.janabadra.ac.id/index.php/informasiinteraktif/article/view/345.

http://www.e-

[3] J. Hutahaean, Konsep Sistem Informasi. Yogyakarta: Deepublish, 2015. 
[4] S. S. Utami, "ANALISIS PENERAPAN ENTERPRISE RESOURCE PLANNING ( ERP ) ( Studi pada PT Domusindo Perdana )," vol. 33, no. 1, pp. 165-170.

[5] D. R. Rahadi, "Pengukuran Usability Sistem Menggunakan Use Questionnaire Pada Aplikasi Android Interface pengguna Android didasarkan pada manipulasi langsung menggunakan masukan sentuh yang serupa dengan tindakan di dunia nyata, seperti menggesek ( swiping ), mengetuk ," vol. 6, no. 1, pp. 661-671, 2014.

[6] A. Nita Rosa Damayanti, Dedi Rianto Rinaldi, "Evaluasi Website Pascasarjana Magister Teknik Informatika Universitas Bina Darma Palembang Menggunakan Usability Testing," 2014.

[7] W. Handiwidjojo and L. Ernawati, "Pengukuran Tingkat Ketergunaan ( Usability ) Sistem Informasi Keuangan Studi Kasus : Duta Wacana Internal Transaction ( Duwit )," vol. 02, no. 01, 2016.

[8] M. R. Pahlevi and D. Thamrin, "Evaluasi Website E-Ticketing dengan Menggunakan Metode Usability Testing dan Wammi," vol. 13, no. 2, 2018.

[9] D. Abdul, Fuji, "Pengujian Hipotesis Penelitian Survey Usability Website ResearchGate Pengujian Hipotesis Penelitian Survey Usability Website ResearchGate Menggunakan SmartPLS," Researchgate, no. November, 2019.

[10] P. D. Sugiyono, Metode Penelitian Kombinasi (Mixed Methods). JL.Gegerkalong Hilir No.84 Bandung: Alfabeta, cv, 2018.

[11] S. MAISAROH, "EVALUASI KOMPONEN USABILITY PADA WEBSITE FMIPA UNIVERSITAS RIAU DENGAN MENGGUNAKAN PENDEKATAN METODE HEURISTIC EVALUATION," 2018.

A. P. Abuzar Asra, Puguh Bodro Irawan, Metode Penelitian Survei. Bogor: Penerbit In Media, 2015. 
Halaman ini Sengaja Dikosongkan 